\title{
Catalytic C,C-bond forming additions to unsaturated fatty compounds
}

\author{
Ursula Biermann* and Jürgen O. Metzger \\ University of Oldenburg, Department of Chemistry, D-26111 Oldenburg, Germany
}

\begin{abstract}
A large number of novel fatty compounds have been synthesized by catalytic $\mathrm{C}, \mathrm{C}$-bond forming addition reactions to the $\mathrm{C}, \mathrm{C}$ double bond of unsaturated fatty compounds. Radical reactions such as the solvent-free addition of $\alpha$-halocarboxylic acid esters initiated by electron transfer, e.g., from copper to give fat-derived $\gamma$-lactones are described as well as Lewis acid-induced electrophilic addition reactions yielding new oleochemicals such as alkyl-substituted 4-chlorotetrahydropyrans, primary homoallylic alcohols, $\beta$-, $\gamma$-unsaturated ketocarboxylic acids and Diels-Alder addition products. New catalysts as, e.g., ligandmodified rhodium catalysts for the hydroformylation and heterogeneous boron-modified rhenium catalysts for the olefin metathesis have been developed. The addition of C-nucleophiles such as dimethylmalonate and nitromethane is possible by palladium-(0)catalyzed additions to unsaturated fatty compounds after conversion of the electron-rich to an electron-poor double bond. More than fifty literature articles are reviewed.
\end{abstract}

KEY WORDS: renewable raw materials; unsaturated fatty acids; C,C-bond forming reactions; catalysts; Lewis acids.

\section{Introduction}

Recently, modern synthetic methods have been applied extensively to fatty compounds for the selective functionalization of the alkyl chain. Radical, electrophilic, nucleophilic, and pericyclic as well as transition metal-catalyzed additions to the C,C-double bond of, for example, oleic acid as the prototype of a readily accessible, unsaturated fatty acid have led to a large number of novel fatty compounds [1-6]. Great interest has been focused on carbon-carbon bond-forming addition reactions that afford new branched chain or elongated fatty compounds with possibly interesting properties.

We report here how the C,C-double bond of unsaturated fatty compounds (1-10, figure 1) can be functionalized by formation of new C,C-bonds by catalytic reactions. Up to now there are only a few reactions known that proceed by catalytic reaction conditions. Many Lewis acid induced addition reactions of unsaturated fatty compounds give interesting modified oleochemicals in good yields but an excess of the Lewis acid is required because the carbonyl group of the fatty acid or acid ester is also complexed. A great challenge should be the development of new and effective catalysts, and of catalytic reactions that allow the selective transformation of fatty compounds to give new products with interesting properties.

\footnotetext{
* To whom correspondence should be addressed.

E-mail: ursula.biermann@uni-oldenburg.de
}

\section{Radical additions}

Unsaturated fatty compounds are alkenes having an electron-rich C,C-double bond that can be functionalized by free radical additions with the formation of a new C,C-bond. Free radical addition reactions initiated by different catalysts have been investigated systematically [7].

\subsection{Manganese(III)acetate initiated additions}

Manganese(III)acetate was found to be a good initiator for the addition of enolizable compounds such as acetone, acetic acid, malonic acid, monomethyl malonate and cyanoacetic acid to unsaturated fatty compounds [8,9]. A regioisomeric mixture of 9- and 10acetonyloctadecanoic acid methyl esters $\mathbf{1 1}$ was obtained on reaction of methyl oleate $\mathbf{1 b}$ and acetone in the presence of manganese(III)acetate (scheme 1(a)), while addition of copper(II)acetate to the reaction mixture yielded the regioisomeric $(E)$-configured alkenes $\mathbf{1 2}$ with high stereoselectivity (scheme 1(b)). Methyl 13-oxotetradecanoate $\mathbf{1 3}$ was formed in the respective reaction with methyl 10-undecenoate $\mathbf{6 b}$ (scheme 1(c)). Manganese(III)acetate which is usually required in stoichiometric amounts is generated in situ from potassium permanganate and a catalytic amount of manganese(II)acetate. In this case, only $20 \%$ total manganese(III)salt is required.

The manganese(III)acetate-initiated reaction of methyl oleate $\mathbf{1 b}$ and malonic acid afforded a regioisomeric mixture of $\gamma$-lactones $\mathbf{1 4}$ (scheme 2). The regeneration of manganese(III)acetate was possible by anodic oxidation [10]. 


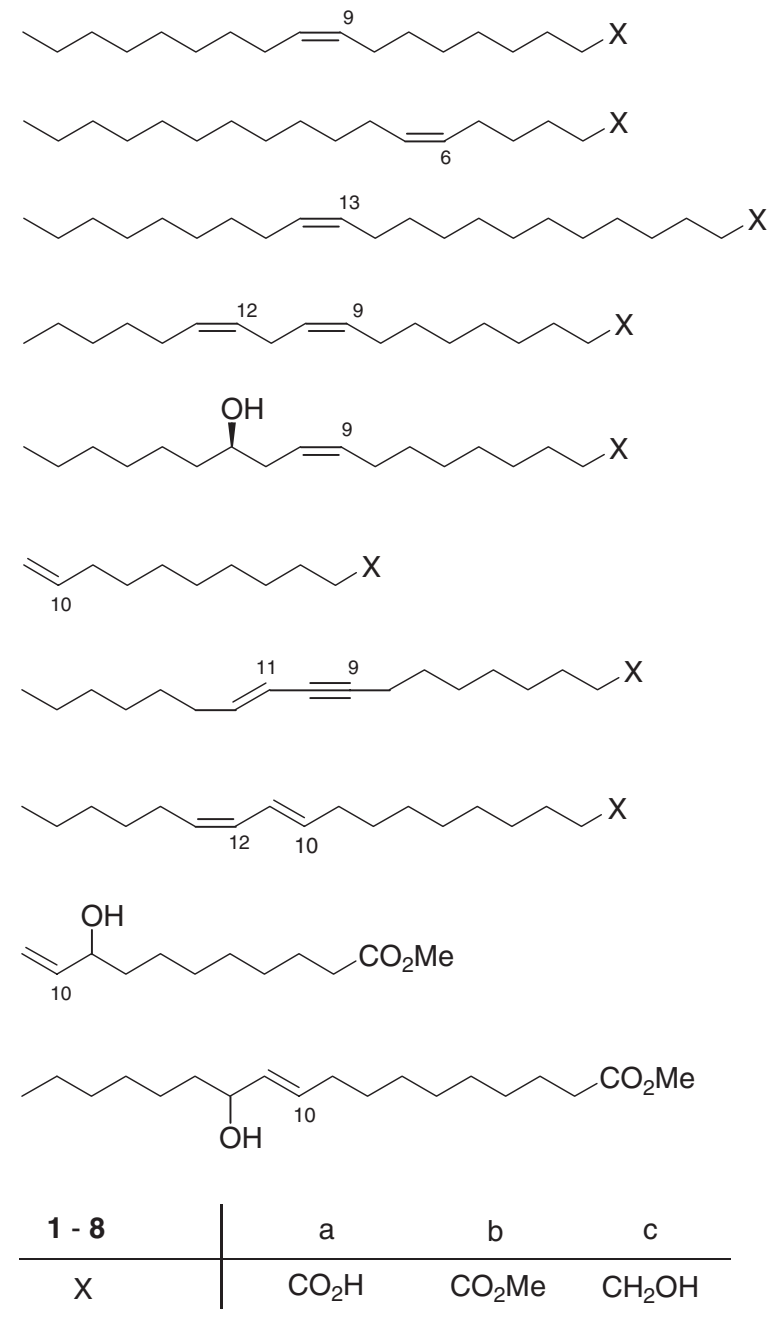

5

6

7

8

9

10

Figure 1. Starting materials for the synthesis of novel fatty compounds: oleic acid 1a, petroselinic acid $\mathbf{2 a}$, erucic acid $\mathbf{3 a}$, linoleic acid $4 \mathbf{a}$, ricinoleic acid $\mathbf{5 a}, 10$-undecenoic acid $\mathbf{6 a}$, santalbic acid $\mathbf{7 a}$, conjuenoic acid $\mathbf{8 a}$ (regio and stereoisomeric mixture), the respective methyl esters $\mathbf{1 b}-\mathbf{8 b}$, and alcohols $\mathbf{1 c - 8 c}$, methyl 9-hydroxy-10undecenoate 9, methyl 12-hydroxyoctadec-10-enoate $\mathbf{1 0}$.

The reaction was applied to 1-alkenes such as methyl 10 -undecenoate $\mathbf{6 b}$ to give the spiro-di- $\gamma$-lactone $\mathbf{1 5}$ as a mixture of diastereomers (figure 2) [9].

\subsection{Copper-initiated additions}

The reaction of higher carboxylic acids and unsaturated fatty compounds can be carried out in a solventfree reaction by addition of their $\alpha$-haloesters initiated by electron transfer from copper [11-13]. The addition of 2-iodocarboxylates, for example, methyl 2-iodopropanoate $\mathbf{1 6}$ to $\mathbf{6 b}$ gave the $\gamma$-lactone $\mathbf{1 7}$ in high yields (scheme 3).

The reaction procedure is very simple: The unsaturated fatty compound, the 2-halocarboxylate and commercial copper powder are mixed without further pretreatment and heated at $100-130^{\circ} \mathrm{C}$ under an inert a)<smiles>CCCCCCCCCC(CCCCCCCOCCOC(C)=O)CC(C)=O</smiles>

b)<smiles>CCCCCCCC=CC(CCCCCCCC(C)=O)CC(C)=O</smiles><smiles>CCCCCCCCC(C=CCCCCCCC(C)=O)CC(C)=O</smiles>

c)<smiles>COC(C)CCCCCCCCCCCC(C)=O</smiles>

13

Scheme 1. Manganese(III)acetate generated in situ from $\mathrm{KMnO}_{4}$, and catalytic amounts of $\mathrm{Mn}(\mathrm{OAc})_{2}$-induced radical addition of acetone to methyl oleate 1b with formation of (a) methyl 9(10)acetonyloctadecanoate 11; (b) in the presence of copper(II)acetate, the regioisomeric methyl 9(10)-acetonyloctadecenoates 12 were obtained; (c) addition of acetone to methyl 10-undecenoate $\mathbf{6 b}$ gave the linear 13oxotetradecanoic acid methyl ester 13 [8,9].

atmosphere. After a simple workup, analytically pure products are obtained in good yields.

The reaction is initiated by electron transfer from copper to the activated iodoalkane (figure 3). The electrophilic radical formed after cleavage of the halide adds to the electron-rich double bond of the alkene, and subsequent iodo abstraction yields a methyl 4-iodoalkanoate that cyclizes to give a $\gamma$-lactone with elimination of iodoalkane.

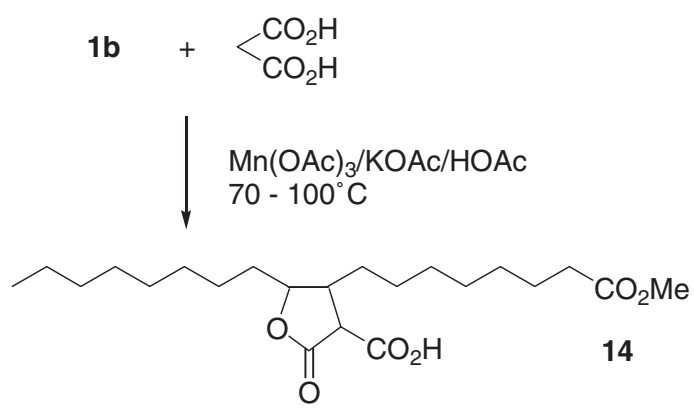

Scheme 2. Manganese(III)acetate-induced radical addition of malonic acid to methyl oleate $\mathbf{1 b}$ with formation of the regioisomeric $\gamma$-lactones 14 [7-9]. 


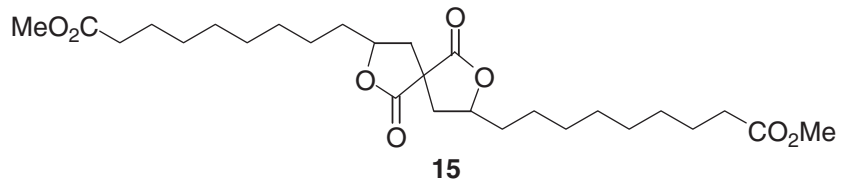

Figure 2. Manganese(III)acetate induced radical addition of malonic acid to methyl 10 -undecenoate $\mathbf{6 b}$ with formation of the spiro-di- $\gamma$ lactone 15 (mixture of diastereomers) [9].

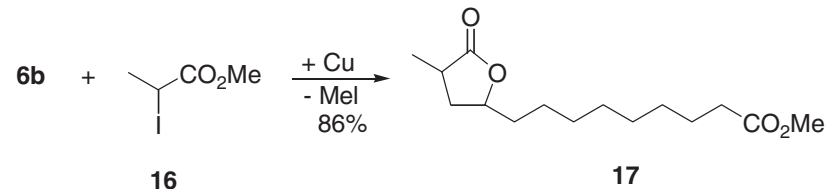

Scheme 3. Copper-initiated addition of methyl 2-iodopropanoate $\mathbf{1 6}$ to methyl 10-undecenoate $\mathbf{6 b}$ [12].

2-Iodocarboxylates were generated in situ from the readily available bromo compounds by addition of a stoichiometric amount of sodium iodide. The addition of methyl 2-bromopropanoate $\mathbf{1 8}$ to methyl oleate $\mathbf{1 b}$ resulted in the formation of the regioisomeric $\gamma$-lactones 19 in $58 \%$ yield (scheme 4 ).

Comparable results were obtained with methyl petroselinate $\mathbf{2 b}$ and methyl erucate $\mathbf{3 b}$.

It is remarkable that the respective reactions of methyl 10-undecenoate $\mathbf{6 b}$ with diethyl bromomalonates could be carried out without addition of sodium iodide. Addition products from $\mathbf{6 b}$ and diethyl 2-bromo-2methylmalonate (21) [10,11] or dimethyl 2-bromo-3ethylsuccinate 23 [13] were formed in 87 and 50\%, respectively (scheme 5 ).

The addition of 2-iodo- and 2-bromo-alkanenitriles is possible in an analogous manner to the addition of alkyl 2-haloalkanoates. While the copper-initiated reaction, e.g., of iodoacetonitrile $\mathbf{2 5}$ and methyl 10-undecenoate 6b gave 12-cyano-10-iodododecanoic acid methyl ester 26 without problems, the corresponding reaction of 2bromo-hexanonitrile $\mathbf{2 7}$ and $\mathbf{6 b}$ required the addition of sodium iodide to give addition product $\mathbf{2 8}$ (scheme 6) [14].

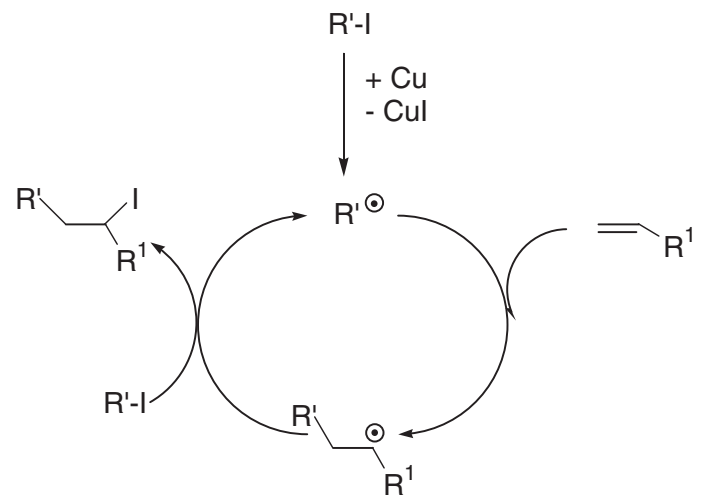

Figure 3. Mechanism for the copper-initiated addition of activated iodoalkanes to alkenes $\left(\mathrm{R}^{\prime}-\mathrm{I}=\right.$ alkyl 2-iodoalkanoate $[\mathbf{1 6}]$, $\left.R^{1}=\operatorname{alkyl},\left(\mathrm{CH}_{2}\right)_{8} \mathrm{COOMe}\right)$.

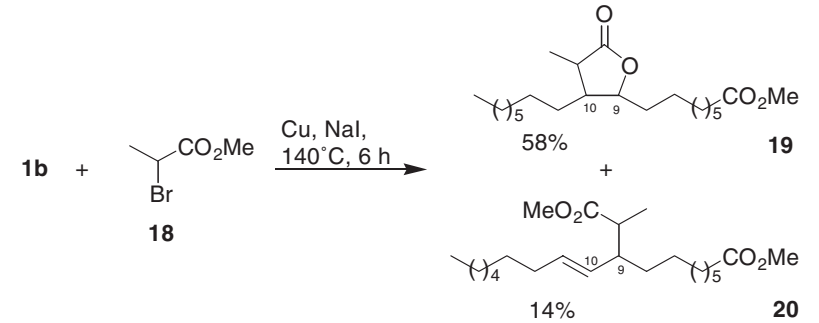

Scheme 4. Copper-initiated addition of methyl 2-bromopropanoate 18 to methyl oleate $\mathbf{1 b}$ in the presence of sodium iodide yields the regioisomeric $\gamma$-lactones $\mathbf{1 9}$ and the addition elimination product 20 [11-13].

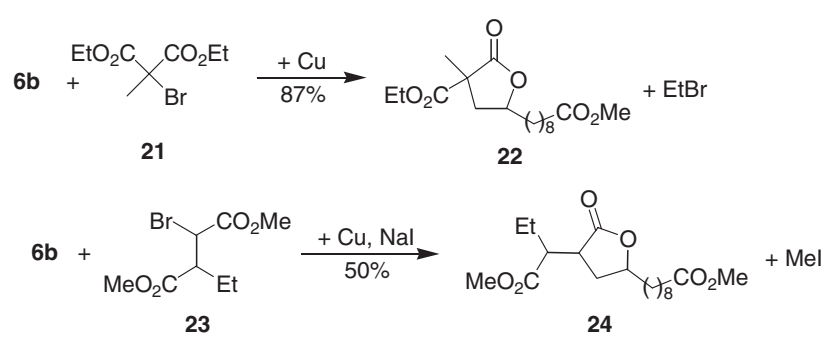

Scheme 5. Copper-initiated addition of diethyl 2-bromo-2-methylmalonate $(\mathbf{2 1})[11,12]$ and ethyl 2-bromo-3-ethylsuccinate 23 [14] to methyl 10 -undecenoate $\mathbf{6 b}$ in the presence of sodium iodide.

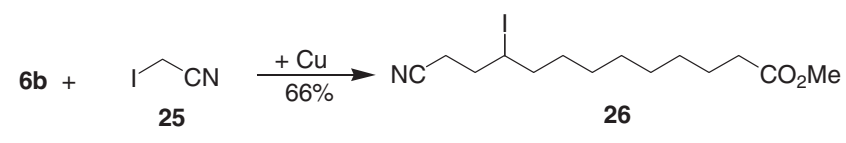

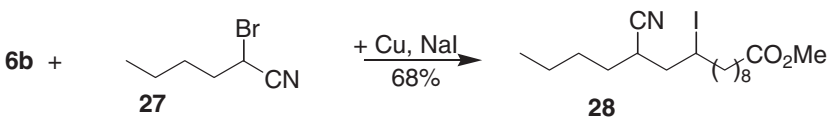

Scheme 6. Copper-initiated addition of iodoacetonitrile 25 and 2 bromohexanonitrile 27 to methyl 10-undecenoate $\mathbf{6 b}$ [14].

Furthermore, the reaction was applied to intramolecular cyclizations [15]. Referring to reaction time, yield and stereoselectivity, $\mathrm{SnCl}_{2} / \mathrm{AgOAc}$ (scheme 7) was found to be the most effective initiator system for the cyclization of methyl 2-iodopetroselinate $\mathbf{2 9}$ to cyclopentane derivatives $\mathbf{3 0}$.

Perfluoroalkylated oleochemicals, which are of interest because of their surfactant properties [16], can be

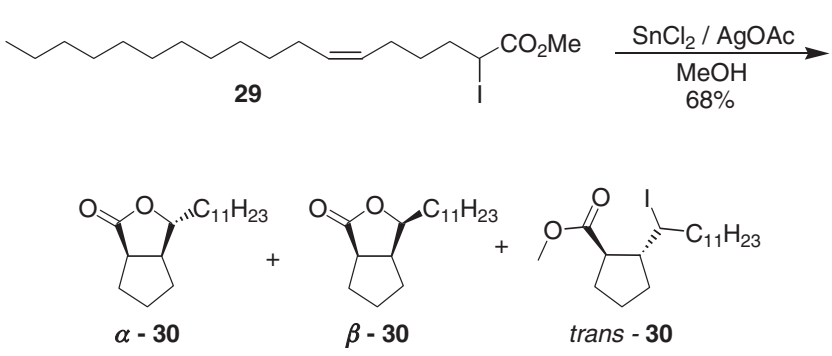

Scheme 7. Radical cyclization of methyl 2-iodopetroselinate 29 induced by $\mathrm{SnCl}_{2} / \mathrm{AgOAc}(\alpha-\mathbf{3 0}: \beta-\mathbf{3 0}:$ trans-30 $=35: 31: 34)[14]$. 


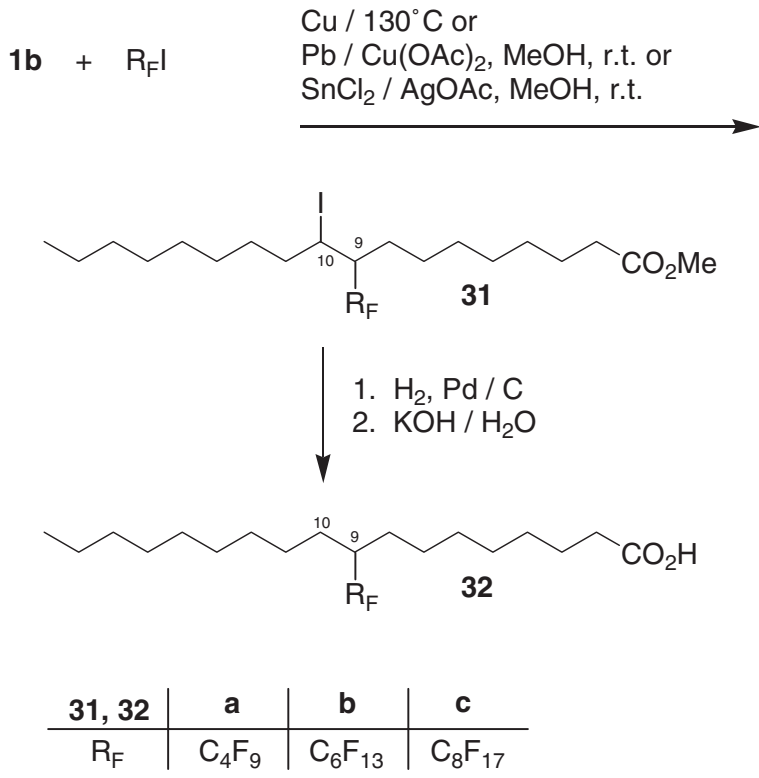

Scheme 8. Synthesis of 9- and 10-perfluoroalkyloctadecanoic acids 32 as a regioisomeric mixture: Addition of perfluoroalkyl iodides to $\mathbf{1 b}$ gave the regioisomeric perfluoroalkylated iodoesters 31, which were then reduced to iodine-free esters and hydrolyzed to free perfluoroalkylated fatty acids 32 [17,18].

synthesized by electron transfer radical reactions initiated by metals such as finely divided silver [17], copper powder [18], or lead with a catalytic amount of copper(II)acetate [18].

The best yields of perfluoroalkylated fatty compounds 31 from reactions of methyl oleate $\mathbf{1 b}$ and perfluoroalkyl iodides were obtained with copper powder or with lead $/ \mathrm{Cu}(\mathrm{OAc})_{2}$ (scheme 8) [18].

\section{Lewis acid-induced electrophilic additions}

\subsection{Additions of aldehydes and ketones}

Formaldehyde and higher aldehydes react with unsaturated fatty compounds in the presence of aluminum chloride to form the corresponding alkylsubstituted 4-chlorotetrahydropyrans in good yields and with high selectivity [19]. The reaction of two equivalents of formaldehyde with, for example, methyl oleate $\mathbf{1 b}$, gave the 3,5-dialkyl-substituted 4-chlorotetrahydropyran 33 as a mixture of regioisomers and diastereomers (scheme 9).

However, the reaction shows a considerable diastereoselectivity. The products were formed in a ratio of 33a: 33b $=3: 1$. The mechanism of this Prins-type cyclization is outlined in scheme 10 .

The corresponding reaction of methyl ricinoleate $\mathbf{5 b}$ and formaldehyde proceeded regioselectively to position C9 of the molecule chain yielding a diastereomeric mixture of products 34 (scheme 11) [19]. Using a higher amount of $\mathrm{AlCl}_{3}$ compared to the respective reaction of 1b (scheme 9), the reaction time could be shortened to $3 \mathrm{~h}$.

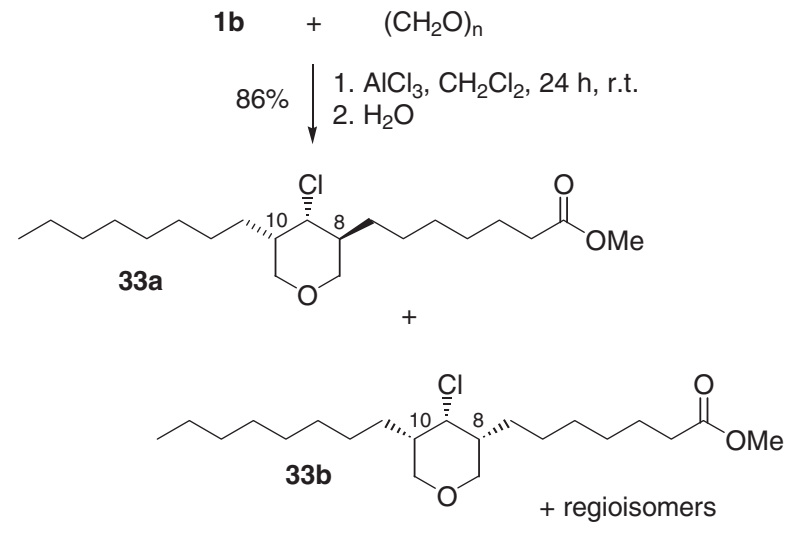

methyl oleate: paraformaldehyde: $\mathrm{AlCl}_{3}=2: 4: 1$

Scheme 9. $\mathrm{AlCl}_{3}$-induced addition of two equivalents of paraformaldehyde to methyl oleate $\mathbf{1 b}$ to give the 4-chlorotetrahydropyrans $\mathbf{3 3}$ (33a: 33b $=3: 1$; mixture of regioisomers) [19].

The synthesis of fat-derived tetrahydropyrans in the presence of montmorillonite clays, which are heterogeneous catalysts with Brønsted- and Lewis acid centers, should be of interest. Heterogeneous catalysts show considerable advantages compared to homogeneous catalysts especially because of their environmental compatibility, reusability, low cost and simple removal by filtration or centrifugation.

The Fe(III)cation-exchanged montmorillonite K10induced reaction of methyl 10-undecenoate $\mathbf{6 b}$ and formaldehyde gave the dimeric tetrahydropyranol ester 35 as the main product, which was isolated in $45 \%$ yield as a diastereomeric mixture (scheme 12) [20].

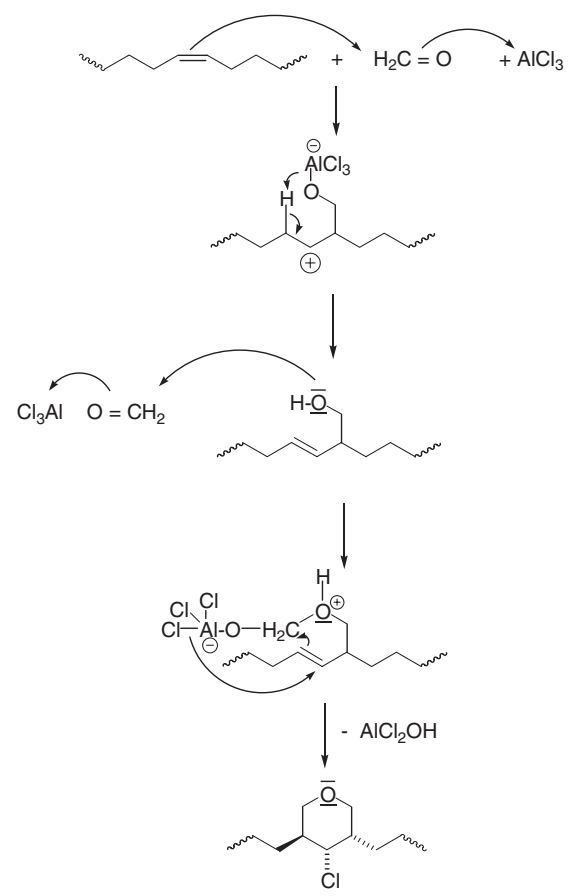

Scheme 10. Mechanism of the $\mathrm{AlCl}_{3}$-induced Prins-type cyclization to give diastereoselectively tetrahydropyran derivatives (the major diastereomer is given). 


$$
\begin{aligned}
& \text { 5b } \quad+\left(\mathrm{CH}_{2} \mathrm{O}\right)_{n} \\
& 79 \% \quad \begin{array}{l}
\text { 1. } \mathrm{AlCl}_{3}, \mathrm{CH}_{2} \mathrm{Cl}_{2}, 3 \text {, r.t. } \\
\text { 2. } \mathrm{H}_{2} \mathrm{O}
\end{array}
\end{aligned}
$$<smiles>CCCCCC[C@@H]1C[C@@H](Cl)[C@H](CCCCCCCC(=O)OC)CO1</smiles><smiles>CCCCCC[C@H]1C[C@@H](Cl)[C@H](CCCCCCCC(=O)OC)CO1</smiles>

34a: m.p. $30-31^{\circ} \mathrm{C},[\alpha]^{20}=27.4\left(\mathrm{c}=2.82, \mathrm{CHCl}_{3}\right)$

5b : paraformaldehyde : $\mathrm{AlCl}_{3}=1: 1.7: 1.7$

Scheme 11. $\mathrm{AlCl}_{3}$-induced addition of one equivalent of paraformaldehyde to methyl ricinoleate $\mathbf{5 b}$ to give 4-chlorotetrahydropyrans $\mathbf{3 4}$ $(\mathbf{3 4 a}: \mathbf{3 4 b}=3.8: 1)[19]$.

In the corresponding reaction of methyl oleate $\mathbf{1 b}$ as main product, 3,5-dialkyl-substituted 4-hydroxytetrahydropyran 36 was obtained as a mixture of regioisomers and diastereomers in $40 \%$ yield (scheme 13) [20]. The byproduct, a dimeric tetrahydropyranol ester was formed in $18 \%$ yield.

It is known from literature that homoallylic alcohols with a terminal C,C-double bond give on reactions with aldehydes the respective 2,6-dialkyl-substituted 4-hydroxytetrahydropyrans in the presence of Amberlyst-15 [21]. This reaction, using montmorillonite KSF as catalyst, was applied to homoallylic alcohols with internal C,Cdouble bonds such as methyl ricinoleate $\mathbf{5 b}$. In the respective reaction with heptanal on the surface of KSF in refluxing dichloromethane, the 2,3,6-trialkyl-substituted tetrahydropyranol 37 was obtained remarkably as a mixture of only two diastereomers in $56 \%$ yield (scheme 14). The all-cis-product $\mathbf{3 7 a}$ was formed with considerable diastereoselectivity. The ratio of compounds 37a : 37b was $2.7: 1$ [20]. Tetrahydropyrans hydroxylated

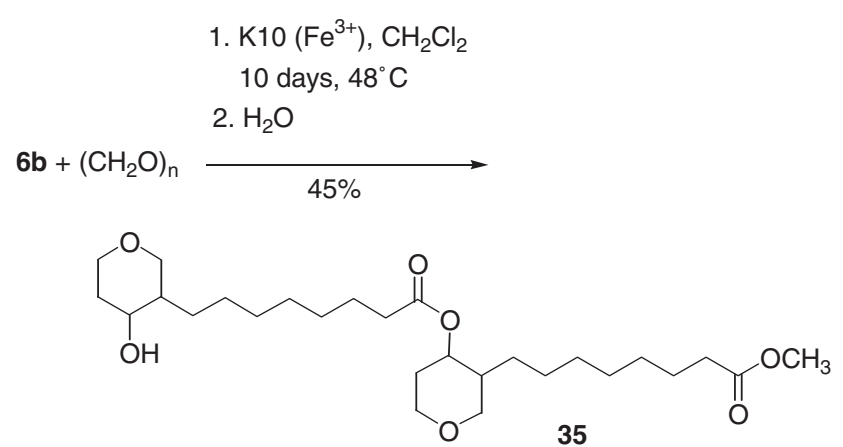

Scheme 12. Addition of formaldehyde to methyl 10-undecenoate $\mathbf{6 b}$ in the presence of $\mathrm{Fe}^{3+}$-exchanged montmorillonite $\mathrm{K} 10$ to give the dimeric tetrahydropyranol ester 35 [20].

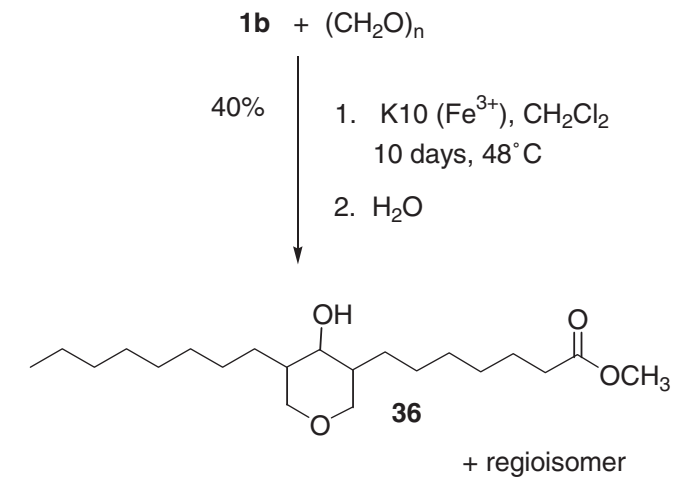

Scheme 13. Addition of formaldehyde to methyl oleate $\mathbf{1 b}$ in the presence of $\mathrm{Fe}^{3+}$-exchanged montmorillonite $\mathrm{K} 10$ to give the 4hydroxytetrahydropyran 36 [20].

at the 4-position are found in a number of natural products [22].

$\omega$-Hydroxycarboxylic acids, including alkyl-branched acids such as $\mathbf{3 8}$, which are of interest as polyester components, are obtained with high selectivity by the ene addition of formaldehyde to unsaturated fatty acids such as 1a (scheme 15) [23,24]. However, stoichiometric amounts of dimethylaluminum chloride $\left(\mathrm{Me}_{2} \mathrm{AlCl}\right)$ or ethylaluminum dichloride $\left(\mathrm{EtAlCl}_{2}\right)$ have to be used as reagents $[25,26]$. The acid (Z)-39 (scheme 14), obtained by the addition of formaldehyde to 10-undecenoic acid $\mathbf{6 a}$, induces wound healing of tissue damage in soybeans by stimulation of callus formation at the damaged site [27].

Ene additions of formaldehyde to natural oils proceed with formation of the respective di- and trifunctionalized triglycerides [28], and jojoba oil gives mixtures of $1: 1$ and $1: 2$ adducts [29]. Homoallyl ethers are obtained in an analogous reaction with acetals [30].

Highly regioselective carbon-carbon bond-forming additions take place when santalbic acid $7 \mathbf{a}$, which is the main fatty acid in the seed oil of sandalwood and which contains a conjugated enyne system, is used as substrate [31]. The $\mathrm{Me}_{2} \mathrm{AlCl}$-induced addition of formaldehyde to

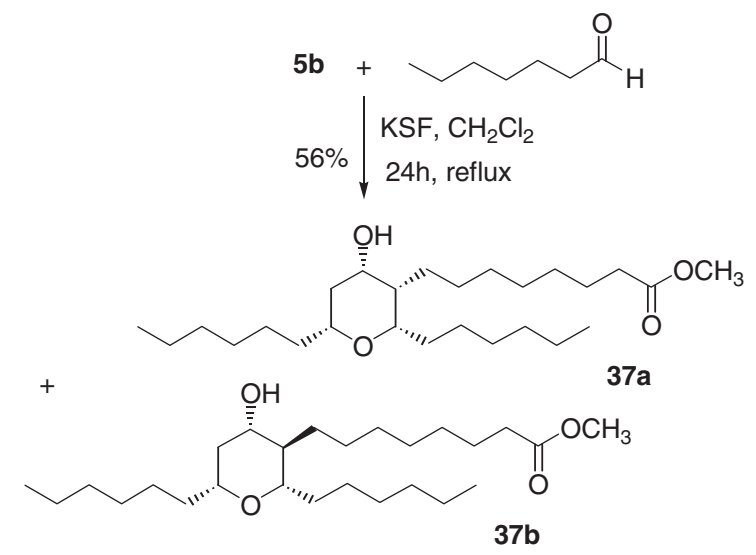

Scheme 14. Addition of heptanal to methyl ricinoleate $\mathbf{5 b}$ in the presence of montmorillonite KSF to give the 4-hydroxytetrahydropyran 37 ([37a]: [37b] $=2.7: 1)[19]$. 


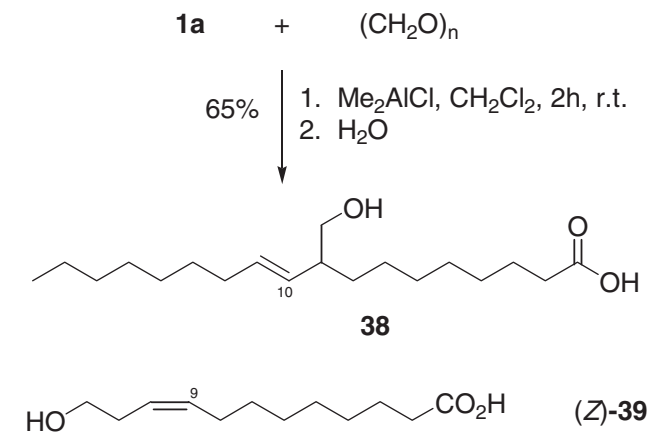

Scheme 15. $\mathrm{Me}_{2} \mathrm{AlCl}$-induced addition of paraformaldehyde to oleic acid 1a to give the homoallyl alcohol $\mathbf{3 8}$ and the regioisomer $(E)-10$ hydroxymethyl-8-octadecenoic acid. The corresponding addition to 10 -undecenoic acid 6a gives the homoallyl alcohol $39[(E):(Z)=4: 1]$ $[23,24]$.

the enyne $\mathbf{7 b}$ afforded the stereoisomeric 10-chloro-9hydroxymethyl fatty acid esters $\mathbf{4 0}$ in $76 \%$ yield (scheme 16). Only two of the eight possible regio- and stereoisomers were obtained $([\mathbf{4 0 a}]:[40 \mathrm{~b}]=1.1: 1)$.

In the presence of ruthenium trichloride, hexachloroplatinum acid, boron trifluoride or tin tetrachloride, formaldehyde was added to methyl oleate 1b ([1)]: [catalyst] $=20: 1$ ) to give mixtures of products that consisted mainly of 2:1-adducts such as methyl 8formyl-10-hydroxyethylstearate and dioxane derivatives [32]. Furthermore, in this reaction, 1:1-adducts such as methyl 9(10)-formylstearate and methyl 9(10)-hydroxymethyl-10(8)-octadecenoate as well as traces of 4:1adducts were formed.

The $\mathrm{SnCl}_{4}$-induced addition of glyoxylic acid ethyl ester to ethyl oleate afforded the regioisomeric ene adducts, while the corresponding reaction with mesoxalic acid diethyl ester $\left[\mathrm{EtO}_{2} \mathrm{CCOCO}_{2} \mathrm{Et}\right]$ gave a product mixture containing the regioisomeric ene adducts and $\gamma$ lactones [33].

\subsection{Ethylaluminum sesquichloride-induced alkylations with alkyl chloroformates}

The alkylation of long-chain unsaturated fatty compounds is of great importance because alkylbranched oleochemicals have interesting properties [34]. They are used for many applications such as lubricants, cosmetics, softeners, defoamers and

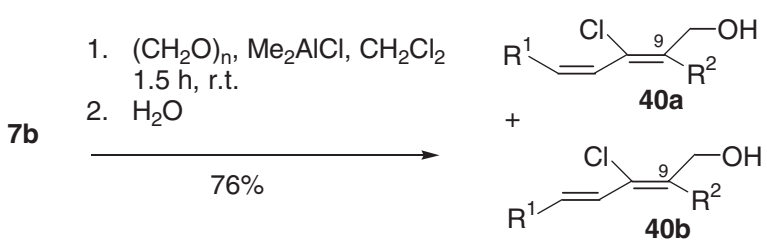

Scheme 16. Regioselective and stereoselective reaction of methyl octadec-11-en-9-ynoate $\mathbf{7 b}$ and paraformaldehyde, induced by dimethylaluminum chloride $\left(\mathrm{Me}_{2} \mathrm{AlCl}\right) \quad[31] ; \mathrm{R}^{1}=\left(\mathrm{CH}_{2}\right)_{5} \mathrm{CH}_{3}$; $\mathrm{R}^{2}=\left(\mathrm{CH}_{2}\right)_{7} \mathrm{COOCH}_{3}$.
$1 a$

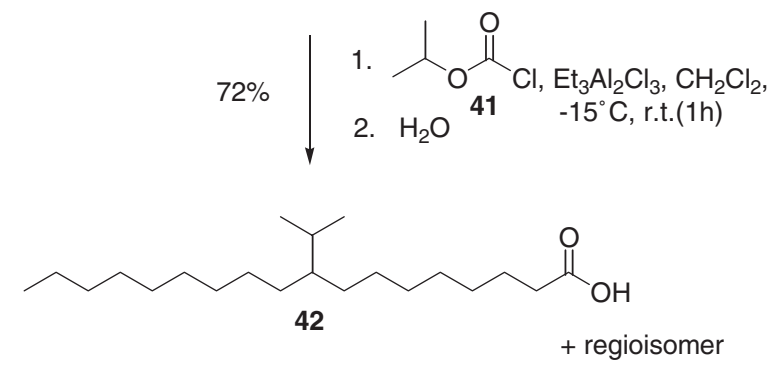

Scheme 17. Ethylaluminum sesquichloride-induced reaction of oleic acid 1a and isopropyl chloroformate $\mathbf{4 1}$ to give the alkylation product 42 [35].

wood-protecting agents. Isostearic acid, a commercially available product, which is obtained as a by-product in the montmorillonite-induced dimerization process of oleic acid, is used, e.g., in the cosmetic and lubricant area. However, the commercial isostearic acid is not at all a pure compound-it consists of a mixture of substances with aromatic and cyclic derivatives among others.

The ethylaluminum sesquichloride $\left(\mathrm{Et}_{3} \mathrm{Al}_{2} \mathrm{Cl}_{3}\right)$-induced Friedel-Crafts alkylation using alkyl chloroformates is a new method for the alkylation of unsaturated fatty compounds [35].

The reaction of oleic acid $\mathbf{1 a}$ with isopropyl chloroformate 41 gave, in the presence of $\mathrm{Et}_{3} \mathrm{Al}_{2} \mathrm{Cl}_{3}$ after a reaction time of $2 \mathrm{~h}$, an approximately $1: 1$ mixture of the regioisomers 9- and 10-isopropyloctadecanoic acid 42 in a yield of 72\% (scheme 17) [35].

In some cases as, e.g., in alkylations of 10-undecenoic acid 6a, addition of a hydride donor such as triethylsilane was necessary. With respect to the wide spectrum of applications for alkyl-branched fatty compounds, it should be of interest to find more effective catalysts for this reaction.

\subsection{Alkylaluminum chloride-induced Friedel-Crafts acylations}

The ethylaluminum dichloride $\left(\mathrm{EtAlCl}_{2}\right)$-induced Friedel-Crafts acylation is an interesting and versatile method for the functionalization of unsaturated fatty compounds yielding the respective $\beta, \gamma$-unsaturated ketones with high selectivity [36-38]. The reaction can be carried out with a great number of different acylating agents such as acyl chlorides, dicarboxylic acid chlorides, cyclic anhydrides, unsaturated acyl chlorides, and aromatic and heteroaromatic acyl chlorides.

The EtAlCl${ }_{2}$-induced acylation of oleic acid $\mathbf{1 a}$, among others, with acyl chlorides 43 gave the $(E)$ configured $\beta$ - $\gamma$-unsaturated oxocarboxylic acids 44 with high selectivity (scheme 18). The acylation products are substrates for a number of interesting follow-up reactions, for example, for Nazarov cyclizations [39]. 


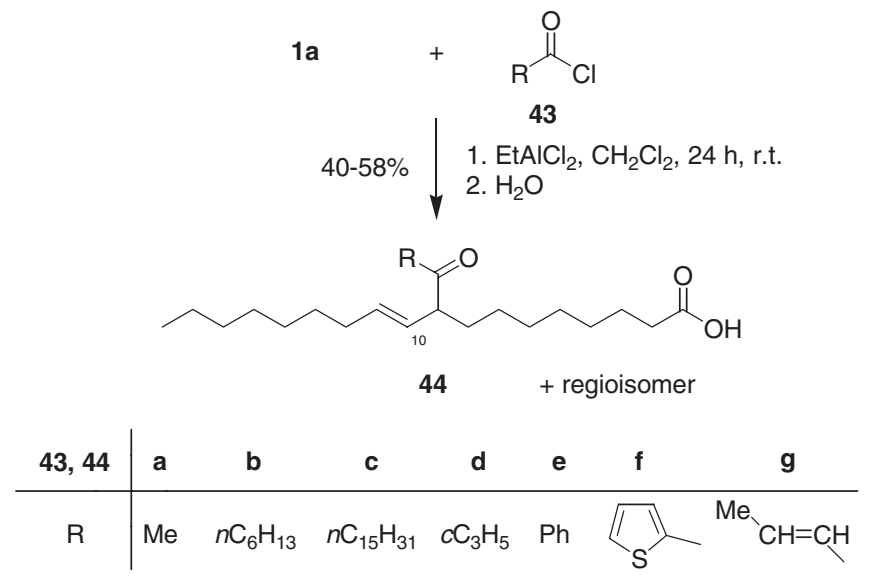

Scheme 18. EtAlCl 2 -induced Friedel-Crafts acylations of oleic acid 1a with the acyl chlorides $\mathbf{4 3 a - g}$ give the unsaturated regioisomeric oxocarboxylic acids 44a-g [36-38].

A modified Nazarov cyclization using montmorillonite clay $\mathrm{K} 10$ as catalyst is described to give after hydrogenation, the cyclopentanone derivative $\mathbf{4 8}$ from the acylation products $\mathbf{4 6}$ of methyl oleate $\mathbf{1 b}$ and $\alpha, \beta-$ unsaturated acyl chlorides $\mathbf{4 5}$ g (scheme 19) [39].

EtAlCl ${ }_{2}$-induced acylations of 1 -alkenes such as methyl 10-undecenoate $\mathbf{6 b}$ yielded the acylated products with high regioselectivity. The acylation, e.g., with thiophene-2-carboxylic acid chloride took place exclusively to position $\mathrm{C} 11$ of the molecule chain to give the 2-thienyl allyl ketone $\mathbf{4 9}$ in 59\% yield (figure 4).

The acylation of methyl santalbate $\mathbf{7 b}$ with heptanoyl chloride was carried out in the presence of $\mathrm{Me}_{2} \mathrm{AlCl}$ (scheme 20) [31]. A new allenic compound $\mathbf{5 0}$ was obtained regioselectively as a diastereomeric mixture in a ratio of approximately $1: 1$.<smiles>COC(=O)CCCCCCC/C=C/CC(=O)c1cccs1</smiles>

Figure 4. 2-Thienyl allyl ketone 49 obtained from the reaction of methyl 10-undecenoate $\mathbf{6 b}$ and thiophene-2-carboxylic acid chloride [38].

Fatty acid derivatives with an allenic system such as $\mathbf{5 0}$ are known to have interesting properties [40], and in special cases, they have been used as substrates in the synthesis of new fatty compounds; one example is as a $\mathrm{C}_{18}$ keto allenic ester for the synthesis of pyrazole ester derivatives [41].

Intramolecular acylations are also possible. The intramolecular reaction of petroselinic acid chloride
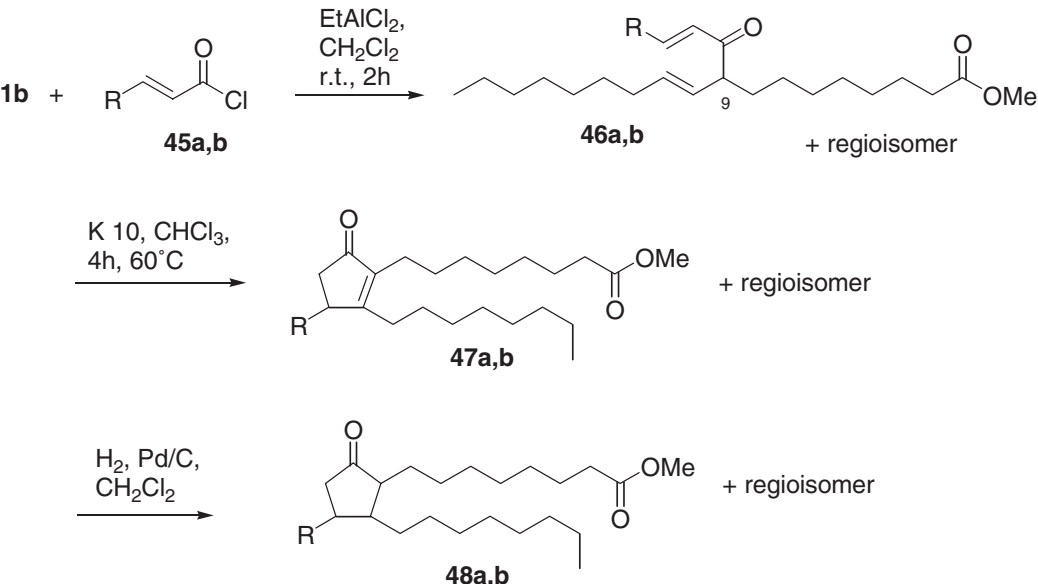

\begin{tabular}{c|cc} 
45 - 48 & a & b \\
\cline { 1 - 1 } & $\mathrm{CH}_{3}$ & $\mathrm{H}$
\end{tabular}

Scheme 19. Et $\mathrm{AlCl}_{2}$-induced Friedel-Crafts acylation of methyl oleate $\mathbf{1 b}$ with $\alpha, \beta$-unsaturated acyl chlorides $\mathbf{4 5} \mathbf{a}$ and $\mathbf{4 5 b}$ followed by Nazarov cyclization of the obtained allyl vinyl ketones $\mathbf{4 6} \mathbf{a}, \mathbf{b}$ to give alkyl-substituted cyclopentenones $\mathbf{4 7} \mathbf{a}, \mathbf{b}$. Catalytic hydrogenation of $\mathbf{4 7} \mathbf{a}, \mathbf{b}$ affords the saturated cyclopentanone derivatives $\mathbf{4 8 a}, \mathbf{b}$ [39]. 


$$
\begin{aligned}
& \text { 1. } \prod_{0} \mathrm{Cl}, \mathrm{Me}_{2} \mathrm{AlCl}, \mathrm{CH}_{2} \mathrm{Cl}_{2} \\
& 7 b \quad 2 . \mathrm{H}_{2} \mathrm{O}
\end{aligned}
$$

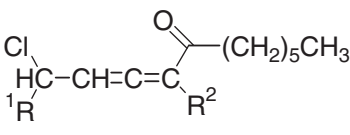

$$
\begin{aligned}
& \mathrm{R}^{1}=\left(\mathrm{CH}_{2}\right)_{5} \mathrm{CH}_{3} ; \mathrm{R}^{2}=\left(\mathrm{CH}_{2}\right)_{7} \mathrm{COOCH}_{3}
\end{aligned}
$$

Scheme 20. Regioselective acylation of methyl santalbate $\mathbf{7 b}$ with heptanoyl chloride, induced by dimethylaluminum chloride [31].

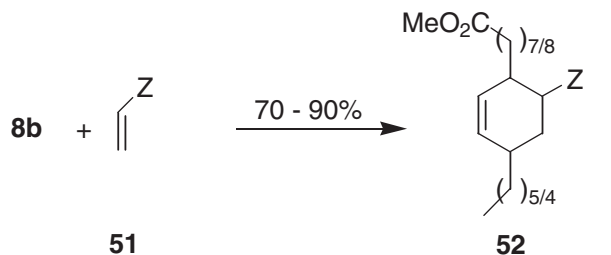

$$
\begin{array}{c|cccc}
\mathbf{5 1 , 5 2} & \mathbf{a} & \mathbf{b} & \mathbf{c} & \mathbf{d} \\
\hline \mathrm{Z} & \mathrm{CN} & \mathrm{CO}_{2} \mathrm{Me} & \mathrm{COMe} & \mathrm{CHO}
\end{array}
$$

Scheme 21. Diels-Alder reactions of methyl conjuenates $\mathbf{8 b}$ with dienophiles 51a-d to the regioisomeric addition products 52a-d [42].

and $\mathrm{EtAlCl}_{2}$ gave $(E)$-2-dodecylcyclohexenone in $58 \%$ yield [37]. The ring closure took place regioselectively at C-6.

\subsection{Diels-Alder reactions}

The Diels-Alder reaction is one of the most important C,C-bond-forming reactions in organic synthesis. Only few examples of reactions that are carried out at high temperatures are described for unsaturated fatty compounds. Schäfer et al., for the first time, reported Lewis acid induced Diels-Alder reactions, which occur at room temperature [42]. Methyl conjuenate $\mathbf{8 b}$ obtained from methyl linoleate $\mathbf{4 b}$ by base-catalyzed isomerization of the C,C-double bonds with dimethylsulfoxide was reacted with different dienophiles $\mathbf{5 1}$ in the presence of boron trichloride or tin tetrachloride, and catalytic amounts of iodine-giving regioisomeric mixtures of Diels-Alder cycloaddition products 52 (scheme 21). Unfortunately, 1-1.8 equivalents of Lewis acid was necessary to accomplish the reaction in an acceptable reaction time while catalytic amounts extended the reaction time dramatically.

Metal triflates, especially $\mathrm{Sc}(\mathrm{OTf})_{3}$ and $\mathrm{Cu}(\mathrm{OTf})_{2}$ were found to be interesting catalysts for Diels-Alder cycloadditions of conjuenoic acid esters [43]. The reaction, e.g., of ethyl conjuenate and methyl vinyl ketone gave a regioisomeric mixture of four $1: 1$ adducts in $81 \%$ yield. It has to be pointed out that the catalyst concentration is only $10 \mathrm{~mol} \%$ and can be reused without loss of yield.

\section{Transition metal-catalyzed reactions}

\subsection{Hydroformylation}

Hydroformylations of unsaturated fatty acid esters and vegetable oils in the presence of rhodium or cobalt catalysts are well known [44-46]. Recently, the hydroformylation of vegetable oils such as soybean, high oleic safflower, safflower and linseed oil using ligand-modified rhodium catalysts was reported. Quantitative yields of hydroformylated oils $\mathbf{5 4}$ were obtained with acetylacetodicarbonylrhodium $\left(\mathrm{Rh}\left(\mathrm{O}_{2}\right) \mathrm{Acac}\right)$ as catalyst precursor in the presence of triphenylphosphine or $(\mathrm{PhO})_{3} \mathrm{P}$ (scheme 22) [47].

The kinetics and the mechanism of the conversion of soybean oil to polyaldehydes using ligand-modified homogeneous rhodium catalysis under the reaction conditions relevant to industrial processes are reported [48].

The hydroformylation of methyl linoleate $\mathbf{4 b}$ in the presence of a heterogeneous rhodium/tert-phosphanecomplex afforded diformylstearate with $60 \%$ selectivity [49].

\subsection{Olefin metathesis}

Following pioneering work of Boelhouwer et al. [50], olefin metathesis was applied by Warwel et al. [51,52] to unsaturated fatty compounds and is an important reaction in oleochemistry. Over the past few years,

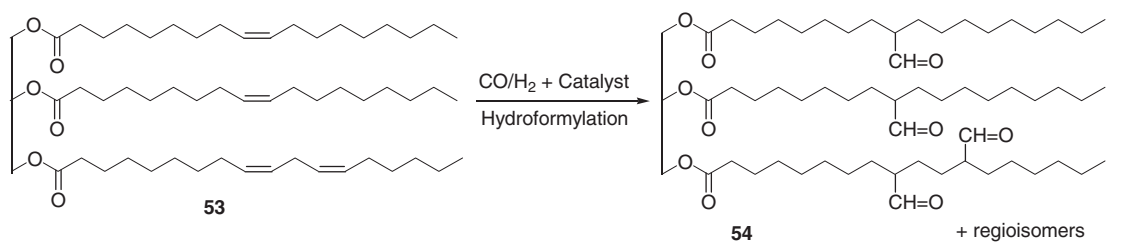

Scheme 22. Hydroformylation of model triglyceride $\mathbf{5 3}$ induced by a ligand-modified rhodium catalyst to give polyaldehyde $\mathbf{5 4}$ [47]. 


$$
\begin{aligned}
& \text { 1b }+\mathrm{H}_{2} \mathrm{C}=\mathrm{CH}_{2} \frac{\text { catalyst }}{20^{\circ} \mathrm{C}, 25-50 \text { bar, } 5-20 \mathrm{~h}} \underset{55}{\longrightarrow} \mathrm{CH}_{2}=\mathrm{CH}\left(\mathrm{CH}_{2}\right)_{7} \mathrm{COOCH}_{3}+\mathrm{H}_{2} \mathrm{C}=\mathrm{CHC}_{8} \mathrm{H}_{17} \\
& \text { catalysts: } \\
& \quad \mathrm{Re}_{2} \mathrm{O}_{7} \cdot \mathrm{B}_{2} \mathrm{O}_{3} / \mathrm{Al}_{2} \mathrm{O}_{3} \cdot \mathrm{SiO}_{2}+\mathrm{SnBu}_{4} \\
& \text { or } \mathrm{CH}_{3} \mathrm{ReO}_{3}+\mathrm{B}_{2} \mathrm{O}_{3} \cdot \mathrm{Al}_{2} \mathrm{O}_{3} \cdot \mathrm{SiO}_{2}
\end{aligned}
$$

Scheme 23. Co-metathesis of methyl oleate $\mathbf{1 b}$ and ethylene to methyl 9-decenoate $\mathbf{5 5}$ and 1-decene. The ester $\mathbf{1 b}$ used (new sunflower) was $87 \%$ pure, the conversions and selectivities each $>90 \%$ and the yields of $\mathbf{5 5}$ were $>80 \%$ [51].

significantly active catalysts such as $\mathrm{Re}_{2} \mathrm{O}_{7}$. $\mathrm{B}_{2} \mathrm{O}_{3} / \mathrm{Al}_{2} \mathrm{O}_{3} \cdot \mathrm{SiO}_{2}+\mathrm{SnBu}_{4}$ and $\mathrm{CH}_{3} \mathrm{ReO}_{3}+\mathrm{B}_{2} \mathrm{O}_{3}$. $\mathrm{Al}_{2} \mathrm{O}_{3} \cdot \mathrm{SiO}_{2}$ have been developed and were successfully tested in a series of metathesis transformations [51]. Scheme 23 illustrates the co-metathesis of methyl oleate $\mathbf{1 b}$ and ethylene to form methyl 9-decenoate $\mathbf{5 5}$ and 1-decene. Similarly, methyl 13-tetradecenoate and 1-decene were obtained from methyl erucate $\mathbf{3 b}$ and ethylene [51]. Furthermore, methyltrioxorhenium was found to be a suitable catalyst for the metathesis of unsaturated fatty compounds [53].

Long chain dicarboxylic acid esters 57 were prepared by metathetical dimerization of ( $\omega$-unsaturated fatty acid methyl esters 56 using highly efficient catalysts such as $\mathrm{Re}_{2} \mathrm{O}_{7} \cdot \mathrm{B}_{2} \mathrm{O}_{3} / \mathrm{Al}_{2} \mathrm{O}_{3} \cdot \mathrm{SiO}_{2}+\mathrm{SnBu}_{4}$ or the homogeneous $\mathrm{Ru}$-carbene complex $\mathrm{Ru}(=\mathrm{CHPh}) \mathrm{Cl}_{2}\left(\mathrm{PCy}_{3}\right)_{3}$ (scheme 23) at catalyst concentrations of $0.01 \mathrm{~mol} \% \mathrm{Ru}$ [54]. Transesterification catalyzed by $\mathrm{Ti}(n-\mathrm{OBu})_{4}$ or $\mathrm{Ca}(\mathrm{OAc})_{2} / \mathrm{Sb}_{2} \mathrm{O}_{3}$ was conducted in a two-step process, yielding the linear aliphatic polyester 58 (scheme 24) [53].

\subsection{Palladium(0)-catalyzed nucleophilic additions}

An interesting method for the functionalization of unsaturated fatty compounds is the nucleophilic addition, which demands a chemical reversal of the polarity of the electron-rich double bond to an electron-poor double bond [55]. If the double bond is conjugated to a carbonyl group, the vinylogous addition of nucleophiles to the double bond becomes possible. Interesting new oleochemicals were synthesized from unsaturated fatty compounds by Michael additions [56,57]. Allylic carbonates were found to be very good substrates for the nucleophilic substitution by palladium(0)-catalysis [58].

The first step in these reactions is the oxidative addition of palladium(0) to the allylic system $\mathbf{A}$ to form a $\sigma$-allylpalladium complex, which quickly decomposes into the more stable $\pi$-allylpalladium complex B, which then undergoes decarboxylation to C (figure 5) [57,58]. The alkoxide is sufficiently basic to deprotonate a number of nucleophiles; in the presence of phosphines, it reacts with complex D. To extend this
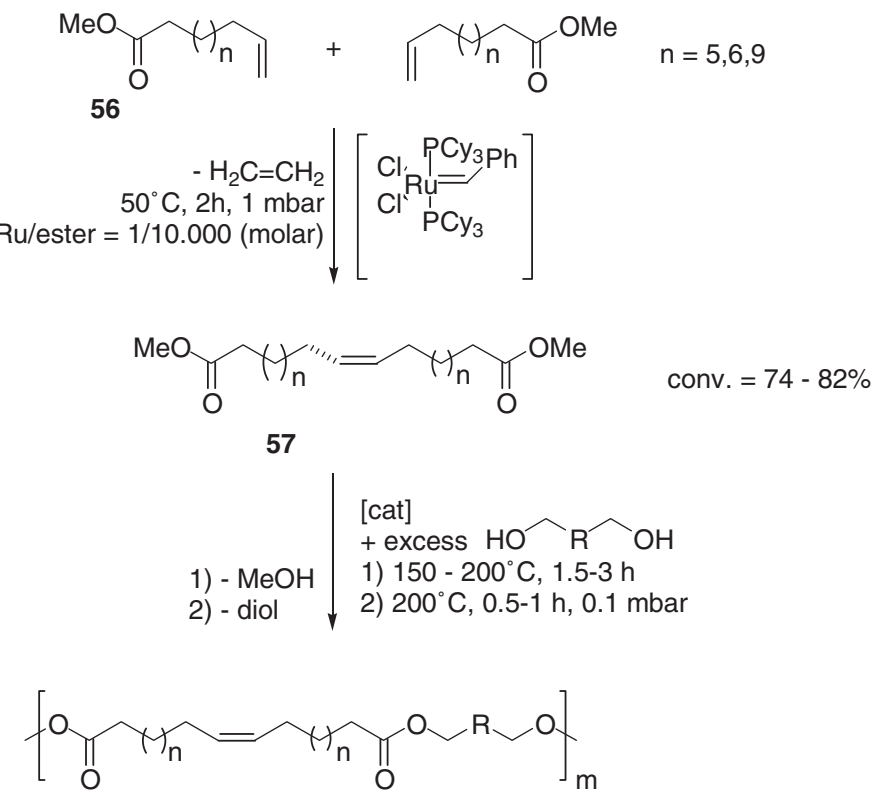

58

$\mathrm{R}=-,-\left(\mathrm{CH}_{2}\right)_{2^{-}},-1,4-$ cyclohexylene $[\mathrm{cat}]=\mathrm{Ti}(\mathrm{O}-n-\mathrm{Bu})_{4}, \mathrm{Ca}(\mathrm{ac})_{2} / \mathrm{Sb}_{2} \mathrm{O}_{3}$

Scheme 24. Metathetical dimerization of $\omega$-unsaturated fatty acid methyl esters $\mathbf{5 6}$ to give long chain dicarboxylic acid esters $\mathbf{5 7}$ and subsequent transesterification with formation of compound $\mathbf{5 8}$ [54]. 


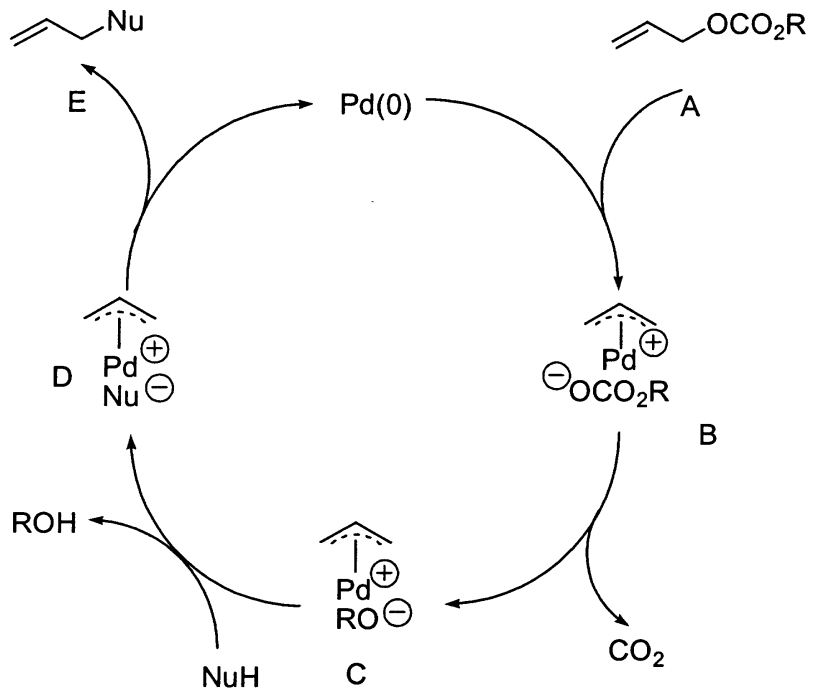

Figure 5. Catalytic cycle for the palladium (0)-catalyzed addition of nucleophiles to allyl carbonates $[57,58]$.

palladium(0)-catalyzed substitution to unsaturated fatty acids, they had to be converted into the respective allyl carbonates.

Michael acceptors derived from fats can be synthesized in different ways, but only the substoichiometric oxidation with selenium dioxide was found to work satisfactorily [56]. The corresponding reactions of methyl 10-undecenoate $\mathbf{6 b}$ and methyl oleate $\mathbf{1 b}$ afforded the allylic alcohols methyl 9-hydroxy-10-undecenoate 9 and methyl 12-hydroxyoctadec-10-enoate $\mathbf{1 0}$ (mixture of regioisomers), respectively. After the reaction, selenium dioxide could be precipitated by petroleum ether and recycled.

Allyl carbonates such as $\mathbf{5 9}$ were obtained from reaction of, e.g., compound 9 with methyl chloroformate in the presence of pyridine in dichloromethane. $\mathbf{5 9}$

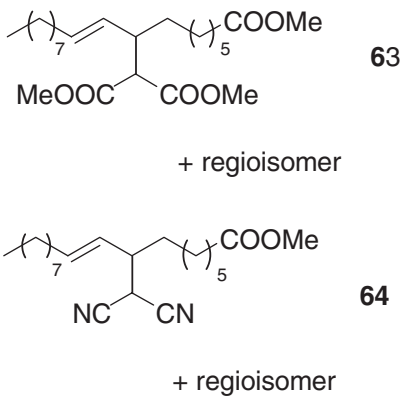

Figure 6. Michael addition products 63 and $\mathbf{6 4}$ obtained by reactions of the allyl carbonate of $\mathbf{1 0}$ with dimethyl malonate and malononitrile, respectively.

was made to react with different carbon nucleophiles such as dimethyl malonate, nitromethane and methyl acetylacetate in the presence of $\mathrm{Pd}\left(\mathrm{PPh}_{3}\right)_{4}$, which was generated from $\mathrm{Pd}_{2}(\mathrm{dba})_{3} \mathrm{CHCl}_{3}(1.0-1.5 \mathrm{~mol} \%)$ and triphenylphosphine (scheme 25) [58].

Addition products 63 and 64 were obtained from reactions of the corresponding allyl carbonate of $\mathbf{1 0}$ with dimethyl malonate and malono dinitrile and were formed as mixtures of regioisomers in 79 and $76 \%$, respectively (figure 6).

\subsection{Synthesis of aromatic compounds}

Aromatic compounds derived from fats can be obtained by transition metal-catalyzed trimerization of the respective alkyne fatty derivatives. The trimerization of, for example, 9-octadecin-1-ol $\mathbf{6 5}$ proceeded by formation of the aromatic compound $\mathbf{6 6}$ in a very good yield (scheme 26) [59]. Highly functionalized pyridine derivatives were synthesized by cotrimerization with nitrile moieties induced by a cobalt complex.

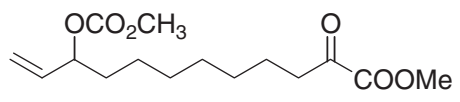

59

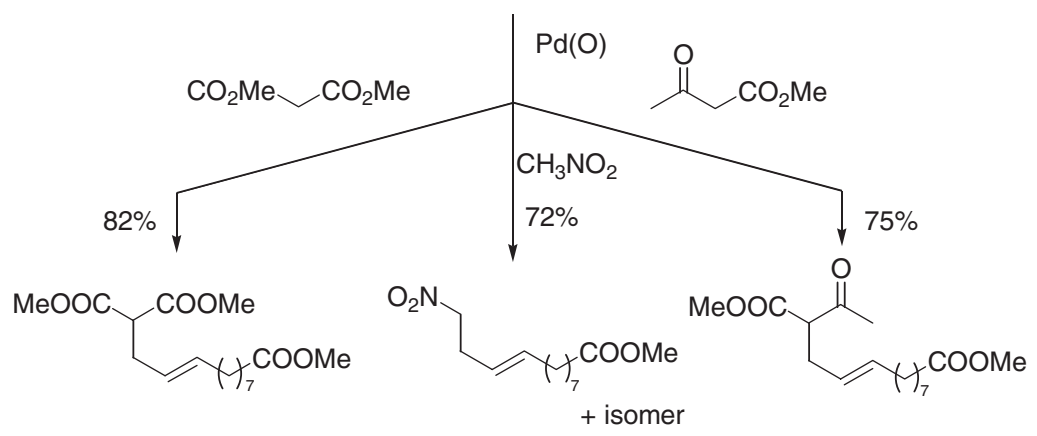

60

61

62

Scheme 25. $\operatorname{Pd}(0)$-catalyzed nucleophilic addition of dimethyl malonate, nitromethane and methyl acetylacetate to the allyl carbonate $\mathbf{5 9}$ to give the substituted methyl undecenoates $\mathbf{6 0}, \mathbf{6 1}, \mathbf{6 2}$ [58] 


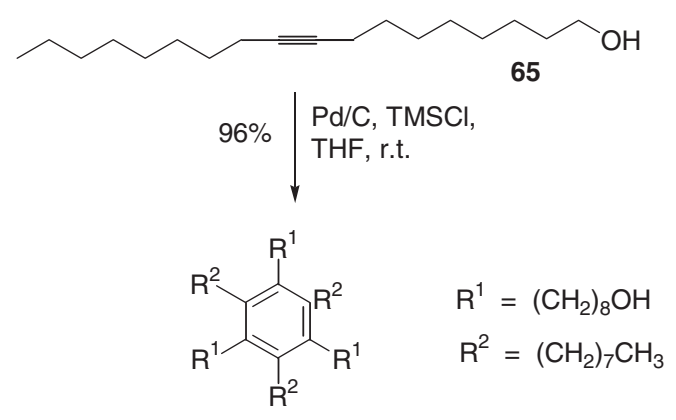

Scheme 26. Cyclotrimerization of alkyne $\mathbf{6 5}$ to give the aromatic compound 66 (TMS-trimethylsilyl) [59].

\section{Conclusion}

This review discussing more than fifty articles of current literature describes the state of the catalytic C,Cbond forming additions to unsaturated fatty compounds. Radical as well as Lewis acid and transition metal-induced additions have been applied to give "tailor-made" products with possibly new and interesting properties. With respect to the importance of unsaturated fatty compounds as renewable raw materials and their application in numerous areas of the chemical industry such as, e.g., monomers in polymer synthesis, lubricants, surfactants, coatings and cosmetics, great efforts have to be made to extend the spectrum of catalytic addition reactions, which are of interest for the selective synthesis of new oleochemicals in the sense of a sustainable development.

\section{References}

[1] U. Biermann, W. Friedt, S. Lang, W. Lühs, G. Machmüller, J.O. Metzger, M. Rüsch gen. Klaas, H. Schäfer and M.P. Schneider, Angew. Chem. Int. Ed. 39 (2000) 2206.

[2] G. Knothe and P. Derksen (eds), Recent Developments in the Synthesis of Fatty Acid Derivatives (AOCS Press, Champaign, Illinois, 1999).

[3] R. Nachwachsende, Perspektiven für die Chemie, M. Eggersdorfer, S. Warwel and G. Wulff (eds) (VCH, Weinheim, 1993).

[4] H. Eierdanz (ed), Perspektiven nachwachsender Rohstoffe in der Chemie, (VCH, Weinheim, 1996).

[5] H. Baumann, M. Bühler, H. Fochem, F. Hirsinger, H. Zoebelein and J. Falbe, Angew. Chem. Int. Ed. Engl. 27 (1988) 41.

[6] U. Biermann, S. Fürmeier and J.O. Metzger, in Oleochemical Manufacture and Applications, F.D. Gunstone and R.J. Hamilton (eds) (CRC Press, LLC, 2001) pp. 266-299.

[7] J.O. Metzger and U. Riedner, Fat Sci. Technol. 91 (1989) 18.

[8] J.O. Metzger and U. Linker, Fat Sci. Technol. 93 (1991) 244.

[9] U. Linker, PhD Thesis (Universität Oldenburg, Germany, 1991).

[10] R. Shundo, J. Nishigushi, Y. Matsubara, M. Toyoshima and T. Harashima, Chem. Lett (1991), 185.

[11] J.O. Metzger and R. Mahler, Angew. Chem. Int. Ed. Engl. 34 (1995) 902.

[12] J.O. Metzger, R. Mahler and G. Francke, Liebigs Ann. (1997) 2303.

[13] R. Mahler, Ph.D. Thesis (Universität Oldenburg, Germany, 1994).
[14] J.O. Metzger, R. Mahler, G. Francke and A. Hayen, in Recent Developments in the Synthesis of Fatty Acid Derivatives, G. Knothe and J.T.P. Derksen (eds) (AOCS Press, Champaign, Illinois, 1999) pp. 90-99.

[15] J.O. Metzger and R. Mahler, Liebigs Ann. (1993) 203.

[16] J. Greiner, A. Manfredi and J.G. Riess, New J. Chem. 13 (1989) 247.

[17] J.O. Metzger and U. Linker, Liebigs Ann. (1992) 209.

[18] J.O. Metzger, R. Mahler and A. Schmidt, Liebigs Ann. (1996) 693.

[19] J.O. Metzger and U. Biermann, Bull. Soc. Chim. Belg. 103 (1994) 393.

[20] U. Biermann and J.O. Metzger, unpublished results.

[21] J.S. Yadav, B.V.S. Reddy, K.C. Sekhar and D. Gunasekar, Synthesis 6 (2001) 885 .

[22] F. Perron and K.F. Albizati, J. Org. Chem. 52 (1987) 4128.

[23] U. Biermann and J.O. Metzger, Fat Sci. Technol. 93 (1991) 282.

[24] J.O. Metzger and U. Biermann, Synthesis (1992) 463.

[25] B.B. Snider, D.J. Rodini, T.C. Kirk and R. Cordova, J. Am. Chem. Soc. 104 (1982) 555.

[26] B.B. Snider and G.B. Phillips, J. Org. Chem. 48 (1983) 464.

[27] E. Blée, INFORM 6 (1995) 852.

[28] J.O. Metzger and U. Biermann, in Chemische Nutzung heimischer Pflanzenöle, R. Fachagentur Nachwachsende (eds) (Landwirtschaftsverlag, Münster, 1998) pp.144-176.

[29] J.F. McLellan, R.M. Mortier, S.T. Orszulik and R.M. Paton, J. Am. Oil Chem. Soc. 71 (1994) 231.

[30] J.O. Metzger and U. Biermann, Liebigs Ann. (1996) 1851.

[31] U. Biermann, A. Lützen, M.S.F. Lie Ken Jie and J.O. Metzger, Eur. J. Org. Chem. (2000) 3069.

[32] A. Behr and H.P. Handwerk, Fat Sci Technol. 94 (1992) 443.

[33] A. Behr and M. Fiene, Eur. J. Lipid Sci Technol. (2000) 212.

[34] D.V. Kinsman, in Fatty Acid in Industry, R.W. Johnson and E. Fritz (eds) (Marcel Dekker, New York, 1989) pp. 233-276.

[35] U. Biermann and J.O. Metzger, Angew. Chem. Int. Ed. 38 (1999) 3675 .

[36] U. Biermann and J.O. Metzger, Fat Sci. Technol. 94 (1992) 329.

[37] J.O. Metzger and U. Biermann, Liebigs Ann (1993) 645.

[38] U. Biermann and J.O. Metzger, in Recent Developments in the Synthesis of Fatty Acid Derivatives, G. Knothe and J.T.P. Derksen (eds) (AOCS Press, Champaign, IL, 1999) pp. 80-89.

[39] J.O. Metzger and U. Biermann, Fett/Lipid 100 (1998) 2.

[40] M.S.F. Lie Ken Jie, Prog. Lipid Res. 32 (1993) 151.

[41] M.S.F. Lie Ken Jie and M.M.L. Lau, Chem. Phys. Lipids, 101 (1999) 237.

[42] M. aus dem Kahmen and H.J. Schäfer, Fett/Lipid, 100 (1998) 227.

[43] A. Behr, M. Fiene, F. Naendrup and K. Schürmann, Eur. J. Lipid, Sci. Technol. (2000) 342.

[44] E.H. Pryde, E.N. Frankel and J.C. Cowan, J. Am. Oil Chem. Soc. 49 (1972) 451.

[45] E.N. Frankel and E.H. Pryde, J. Am. Oil Chem. Soc. 54 (1977) 873.

[46] E.H. Pryde, J. Am. Oil Chem. Soc. 61 (1984) 419.

[47] P. Kandanarachchi, A. Guo and Z. Petrovic, J. Mol. Catal. A Chem. 184 (2002) 65

[48] P. Kandanarachchi, A. Guo, D. Demydov and Z. Petrovic, J. Am. Oil Chem. Soc. 79 (2002) 1221.

[49] B. Fell and B. Meyer, Chemiker Zeitung 115 (1991) 39.

[50] P.B. Van Dam, M.C. Mittelmeijer and C. Boelhouwer, J. Chem. Soc. Chem. Commun. (1972)1221.

[51] B. Wolff, Ph.D. Thesis (RWTH Aachen, Germany, 1994).

[52] S. Warwel, P. Bavaj, M. Rüsch gen. Klaas and B. Wolff, in Perspektiven nachwachsender Rohstoffe in der Chemie, H. Eierdanz (ed.) (VCH, Weinheim, 1996) pp. 119-135.

[53] W.A. Herrmann, W. Wagner, U.N. Flessner, U. Volkhardt and H. Komter, Angew. Chem. Int. Ed. Engl. 30 (1991) 1641.

[54] S. Warwel, F. Büse, C. Demes, M. Kunz and M. Rüsch gen. Klaas, Chemosphere 43 (2000) 39. 
[55] J. Tuji, J. Shimizu, J. Minami, Y. Ohashi and K. Takahashi, J. Org. Chem. 50 (1985) 1523.

[56] R. Maletz, H.J. Schäfer and R. Quermann, Fett/Lipid 98 (1996) 370 .

[57] R. Maletz, Ph.D. Thesis (Universität Münster, Germany, 1994).
[58] H.J. Schäfer and M. Zobel, in Recent Developments in the Synthesis of Fatty Acid Derivatives, G. Knothe and J.T.P. Derksen (eds) (AOCS Press, Champaign, IL, 1999) pp. 59-79.

[59] K. Augustin, Ph.D. Thesis (Universität Münster, Germany, 1991). 